\title{
Effect of process parameters on the adhesion strength in two-component injection moulding of thermoset rubbers and thermoplastics
}

\author{
Gert-Jan Bex ${ }^{1}$, Wim Six ${ }^{2}$, Brittany Laing ${ }^{1}$, Jozefien De Keyzer ${ }^{3}$, Frederik Desplentere ${ }^{2}$, Albert Van Bael ${ }^{1}$ \\ ${ }^{1}$ KU Leuven, Campus Diepenbeek, Materials Technology TC, Wetenschapspark 27, 3590 Diepenbeek, \\ Belgium \\ ${ }^{2}$ KU Leuven, Campus Bruges, Materials Technology TC, Spoorwegstraat 12, 8200 Bruges, Belgium \\ ${ }^{3}$ KU Leuven, Campus Diepenbeek, Sustainable Chemical Process Technology TC, Wetenschapspark \\ 27, 3590 Diepenbeek, Belgium
}

Correspondence to: Gert-Jan Bex (E-mail: gertjan.bex@kuleuven.be)

\begin{abstract}
Recently a novel two-component injection moulding process has been developed for combining thermoplastics with thermoset rubbers. This process is of interest for example when thermoplastic parts include seals which are usually produced out of thermoset rubber. The present study evaluates the influence of different process parameters on the bond strength by means of a half factorial experimental design. The considered process parameters are the mould temperature at the interface, the injection temperature, the injection speed, the holding pressure and the initial roughness of the thermoplastic part at the later interface. The study indicates a large influence of the mould temperature at the interface. Furthermore, the holding pressure only affects the adhesion strength when it is set too low or when the holding time is too short. The other process parameters have no significant effect on the adhesion strength.
\end{abstract}

\section{INTRODUCTION}

Two-component $(2 \mathrm{~K})$ injection moulding is typically used in polymer processing to combine polymers with specific properties without the need of assembling. The technique is often used to combine a hard thermoplastic material with a rubberlike thermoplastic elastomer (TPE) to create a soft touch handle e.g. in a toothbrush. However, when high temperatures, chemical environment or mechanical wear are involved, TPEs do not meet the requirements. For these applications, e.g. medical syringes or products with built-in gaskets like in air valves for engines, it is necessary to replace the TPE material with a thermoset rubber. A technical problem that needs to be overcome is that thermoplastics and thermoset rubbers require fundamentally different process conditions. Thermoplastics are injected at a high temperature and the product is solidified in a cooled mould, while thermoset rubbers are injected at a low temperature and subsequently vulcanised in a heated mould. ${ }^{1,2,3,4}$ To deal with these conflicting requirements, the authors have developed a mould in which the cavities for the thermoplastic part and thermoset rubber part are thermally separated by means of air gaps and an insulation plate. ${ }^{5}$ Both cavities are equipped with separate temperature control facilities. With this setup it is possible to cool the thermoplastic part, preventing it from 
deforming, while vulcanising the thermoset rubber. ${ }^{5}$ Despite the thermal separation, the thermoplastic part will melt at the interface due to the adjacent vulcanising rubber. To prevent the molten interface from failing during ejection, both materials are cooled after the rubber is sufficiently vulcanised, using a rapid heat cycling system. ${ }^{5}$ More details regarding the design of the mould can be found in an earlier study. ${ }^{5}$

For the mechanical quality of the resulting $2 \mathrm{~K}$ product, it is important to achieve sufficient bond strength between both materials during the injection moulding process. Many studies have been conducted investigating the effect of process parameters on bond strength for $2 \mathrm{~K}$ products that consist of two different thermoplastics. A. Islam et al. ${ }^{6,7}$ showed that for acrylonitrile butadiene styrene (ABS) in combination with polycarbonate $(P C)$, the injection and mould temperature of the second component, are the two most significant parameters. These two parameters determine the interface temperature, which needs to be high enough to melt the two polymers together. Another important parameter influencing bond strength is the surface roughness at the interface of the first component. ${ }^{6,7}$ A higher surface roughness both increases mechanical interlocking and contact surface as stated by the authors. Holding pressure only affects bond strength when set too low, a further increase in holding pressure does not have any positive effect on the bond strength. ${ }^{6,7} \mathrm{G}$. Pompe et al. ${ }^{8}$ and D. V. Dobrea et al. ${ }^{9}$ have validated the positive effect of injection and mould temperature on the bond strength for respectively polyamide (PA) with polyurethane (TPU) and highdensity polyethylene (HDPE) with low-density polyethylene (LDPE). D. Y. Huang et al. ${ }^{10}$ also confirmed the influence of both temperatures on the bond strength for polystyrene (PS) in twocomponent injection moulding and successfully modelled it using only these two process parameters. R. A. Carella et al. ${ }^{11}$ proposed a method for selecting optimal process parameters for two-component injection moulding with sufficient bond strength for TPE with polypropylene (PP). In this method, the interface temperature is calculated using the injection and mould temperature of the second component. Both temperatures are set at sufficiently high values in order to ensure that the interface temperature is above the melting point of the first component $\left(160^{\circ} \mathrm{C}\right)$. In a recent study, S. Meister and D. Drummer ${ }^{12}$ were able to increase the positive effect of the mould temperature on the bond strength for PA even more by applying rapid heat cycling during the injection of the second component.

In previous work, the process development was described for realising two-component injection moulding for rubbers with thermoplastics. ${ }^{5}$ In other work, the compatibility between specific rubbers with thermoplastics was demonstrated and techniques were presented to predict the compatibility. ${ }^{13}$ The aim of the present study is the optimisation of the process settings by investigating the effect of the following parameters on the bond strength: mould temperature, injection temperature, holding 
pressure, injection speed and surface roughness of the thermoplastic part at the interface. This was investigated using a half factorial design of experiment.

\section{EXPERIMENTAL}

\section{Materials}

The thermoset rubber used for this parameter study is an ethylene propylene diene monomer (EPDM) rubber, grade 005K from Hercorub NV, with a sulphur-based vulcanisation system. The tensile strength of this specific rubber is $8 \mathrm{MPa}$ and the TC 90 (Time till $90 \%$ Conversion) at $170{ }^{\circ} \mathrm{C}$ is 370 s. The rubber was combined with HDPE grade M80064 from Sabic. It has a yield strength of 32 $\mathrm{MPa}$ and a melting temperature of $135^{\circ} \mathrm{C}$. A second material combination was used to validate the main influencing effect found for the EPDM-HDPE system. A sulphur-based nitrile rubber (NBR) grade 42G from Hercorub NV with a tensile strength of $11 \mathrm{MPa}$ was used for this purpose. The TC 90 of the NBR rubber at $170{ }^{\circ} \mathrm{C}$ is $124 \mathrm{~s}$. This rubber was combined with ABS grade Novodur P2H-AT from INEOS which has a yield strength of $44 \mathrm{MPa}$ and a glass transition temperature of $100^{\circ} \mathrm{C}$.

\section{Method}

\section{Experimental set-up}

The applied injection moulding machine was an Engel 100 ton ES33OH/80V/8OHL-F with a vertical rubber injection unit and a horizontal thermoplastic injection unit. The rubber injection unit is fitted with a $25 \mathrm{~mm}$ screw with an L/D ratio of 16 . The temperature of this unit is externally controlled by a Tool Temp TT-157 E tempering device. The thermoplastic injection unit has a $35 \mathrm{~mm}$ screw with an L/D ratio of 20.

The specimen selected for this study consists of two adjacent plates with a thickness of $2 \mathrm{~mm}$ and other dimensions as shown in Figure 1. 


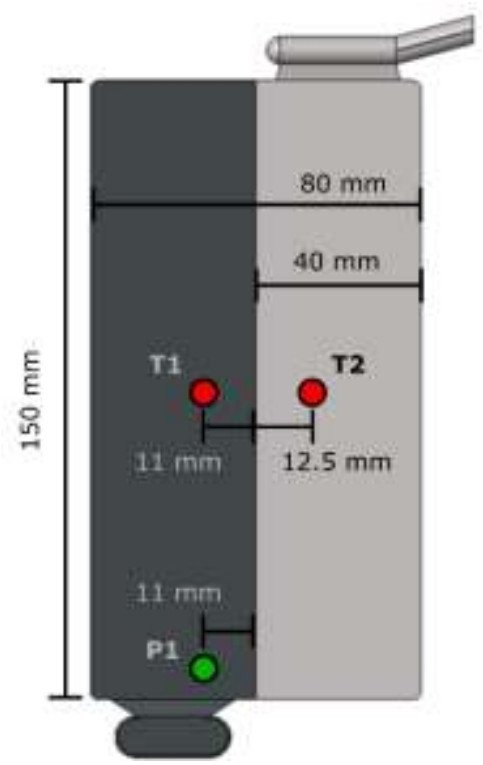

FIGURE 1 Geometry of the test sample with dimensions. The thickness of the part is $2 \mathrm{~mm}$. T1 and T2 indicate two temperature sensors, $\mathrm{P} 1$ is a pressure sensor.

The mould is equipped with thermally separated mould cavities and separate facilities to control the mould temperature for the thermoplastic and thermoset rubber as shown in the introduction. To overcome the problem of molten thermoplastic material at the interface during ejection, the cavity for the rubber is fitted with a rapid heat cycling system making it possible to cool the rubber part before ejecting the product. Two temperature sensors (Priamus 4008B) and a pressure sensor (Priamus 6008A) are fitted in the stationary mould halve on positions T1 and T2, shown in Figure 1. The two-component injection process was implemented by first inserting a metal plate in the mould cavity which is intended for the rubber (Figure 2a). In this way, multiple $1 \mathrm{~K}$ thermoplastic parts (Figure $2 \mathrm{~b}$ ) were produced. Afterwards, the metal insert is removed and $1 \mathrm{~K}$ parts are inserted one by one back into the mould (Figure 2c) before injecting the rubber (Figure $2 \mathrm{~d}$ ). 
a)

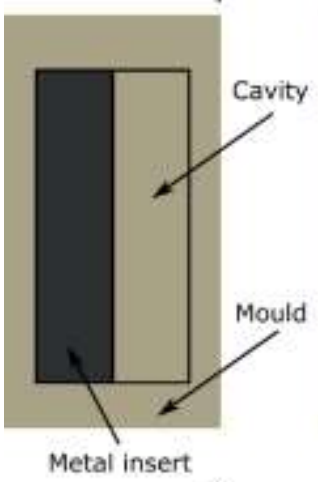

c)

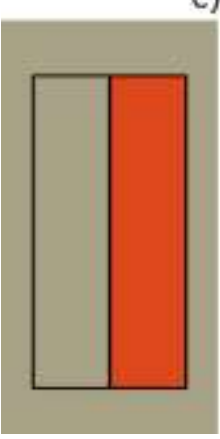

First component

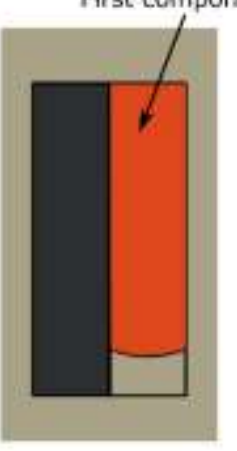

Second component

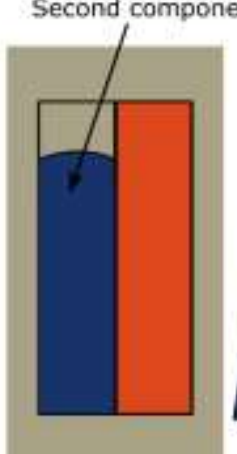

b)

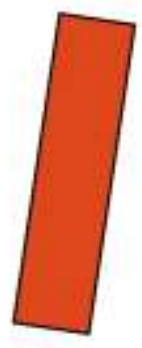

d)

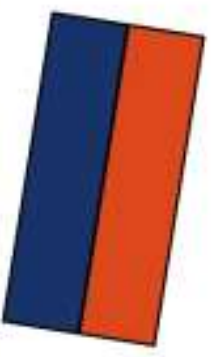

FIGURE 2 Schematic representation of the mould transfer process used in this study. In a) a metal plate is inserted in the cavity of the second component. Multiple $1 \mathrm{~K}$ products are produced as shown in b). In c) these $1 \mathrm{~K}$ products are inserted back into the mould after removing the metal plate. The second component, the rubber, is injected as illustrated in $\mathrm{d}$ ).

\section{Methodology}

The injection moulding parameters for the thermoplastic can be found in Table 1 . These were determined to ensure minimal shrinkage of the part. Thermoplastic parts were moulded two weeks before the start of the actual experiments to ensure that the dimensions of the parts, influenced by post-crystallisation, were stable.

TABLE 1 Process parameters for the thermoplastic part.

\begin{tabular}{lc}
\hline Process parameter & HDPE \\
\hline Injection temperature & $230{ }^{\circ} \mathrm{C}$ \\
Mould temperature & $20{ }^{\circ} \mathrm{C}$ \\
Injection flow rate & $38 \mathrm{~cm}^{3} / \mathrm{s}$ \\
Holding pressure & $790 \mathrm{bar}$ \\
\hline
\end{tabular}

Parameters for the second component, the thermoset rubber, were varied according to a half factorial design of experiment evaluating five parameters at two levels. This results in a $2^{5-1}$ design with resolution five which means that no main effect is aliased with other main effects or two-factor interactions. With this design it is thus possible to analyse both the main effects as the two-factor 
interactions. ${ }^{14}$ Parameters varied in this study are mould temperature at the interface, injection temperature, injection speed, holding pressure and surface roughness of the thermoplastic part at the interface. The mould temperature at the interface was controlled by changing the temperature of the tempering device for the thermoplastic mould cavity, in this experiment between $50^{\circ} \mathrm{C}$ and 60 ${ }^{\circ} \mathrm{C}$ which is in the middle of the range for this specific material combination $\left(40{ }^{\circ} \mathrm{C}-80^{\circ} \mathrm{C}\right)$. The temperature of the tempering device for the rubber was at $180^{\circ} \mathrm{C}$. Resulting mould temperature profiles, measured using a thermal camera (OPTRIS PI400), are presented in Figure 3 together with their upper and lower temperature boundaries. The measured mould interface temperatures for the different settings are $129^{\circ} \mathrm{C}$ and $132{ }^{\circ} \mathrm{C}$. The selected injection temperatures were recommended by the supplier and as confirmed in literature. ${ }^{1,3}$ With a lower temperature the viscosity of the rubber is too high to completely fill the product, with a higher temperature the rubber starts vulcanising in the injection unit. The range for the injection speed was limited by equal viscosity and incomplete filling on one hand and by the machine limits on the other hand. The limits for the holding pressure were selected high enough to completely fill the product, and low enough to minimise flash. The roughness at the interface of the first component, in this case the thermoplastic part, can be adapted by applying a certain roughness to the metal insert (Figure 2a). The negative of this roughness will be replicated in the thermoplastic part during injection moulding. The used roughnesses on the metal inserts are 3.4 and 7.5 Ra $\mu \mathrm{m}$ which are typical values applicable with conventional techniques such as Electrical Discharge Machining (EDM). The different settings for the production of the test samples are presented in Table 2.

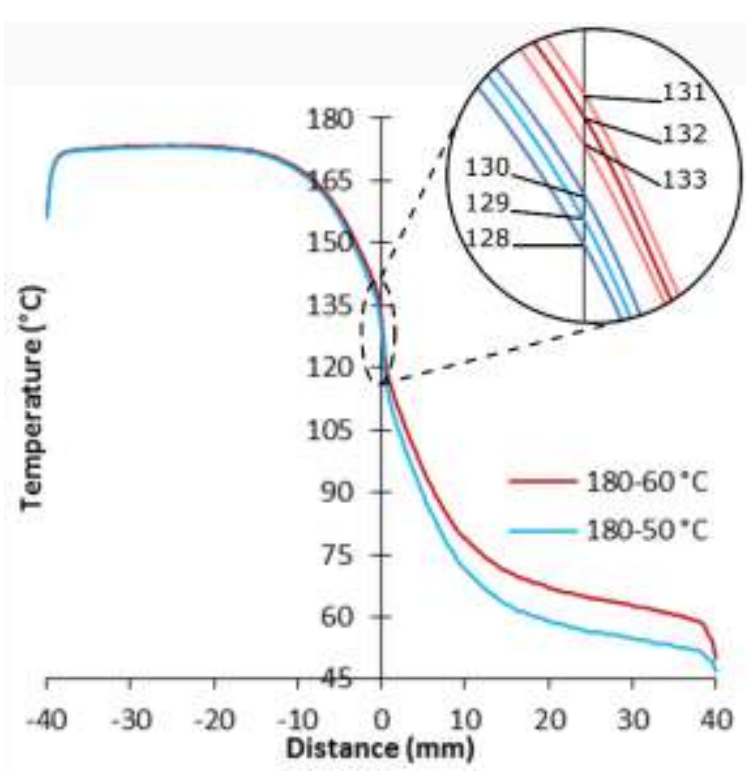

FIGURE 3 Temperature profile of the mould for both temperature settings, made with a thermal camera. Upper and lower limits of the measured mould temperatures within the evaluation zone, are presented within the figure. 
TABLE 2 Different settings for the process parameters used within the experiment.

\begin{tabular}{cccccc}
\hline Setting & $\begin{array}{c}\text { Interface mould } \\
\text { temperature }\left({ }^{\circ} \mathrm{C}\right)\end{array}$ & $\begin{array}{c}\text { Injection } \\
\text { temperature }\left({ }^{\circ} \mathrm{C}\right)\end{array}$ & $\begin{array}{c}\text { Injection speed } \\
\left(\mathrm{cm}^{3} / \mathrm{s}\right)\end{array}$ & $\begin{array}{c}\text { Holding pressure } \\
(\text { bar })\end{array}$ & $\begin{array}{c}\text { Roughness } \\
\text { interface }(\mathrm{Ra} \mu \mathrm{m})\end{array}$ \\
\hline 1 & 129 & 70 & 59 & 149 & 7.5 \\
2 & 129 & 70 & 59 & 198 & 3.4 \\
3 & 129 & 70 & 77 & 149 & 3.4 \\
4 & 129 & 70 & 77 & 198 & 7.5 \\
5 & 129 & 80 & 59 & 149 & 3.4 \\
6 & 129 & 80 & 59 & 198 & 7.5 \\
7 & 129 & 80 & 77 & 149 & 7.5 \\
8 & 129 & 80 & 77 & 198 & 3.4 \\
9 & 132 & 70 & 59 & 149 & 3.4 \\
10 & 132 & 70 & 59 & 198 & 7.5 \\
11 & 132 & 70 & 77 & 149 & 7.5 \\
12 & 132 & 70 & 77 & 198 & 3.4 \\
13 & 132 & 80 & 59 & 149 & 7.5 \\
14 & 132 & 80 & 59 & 198 & 3.4 \\
15 & 132 & 80 & 77 & 149 & 3.4 \\
16 & 132 & 80 & 77 & 198 & 7.5 \\
\hline
\end{tabular}

Each setting was repeated five times and the experiments were conducted in a random order. To ensure complete vulcanisation of the thermoset rubber for each temperature, long vulcanisation times of $2400 \mathrm{~s}$ were used. After the vulcanisation process, the rubber was cooled down to $100^{\circ} \mathrm{C}$ using rapid heat cycling before ejecting the final product.

Tensile tests were used to evaluate the adhesion strength. Rectangular samples with a width of 10 $\mathrm{mm}$ were punched out in the middle of the specimens. Tensile tests were performed on a Zwick Z050 equipped with a $1 \mathrm{kN}$ load cell at a cross-head speed of $200 \mathrm{~mm} / \mathrm{min}$. The results were processed using Minitab 17, main effect plots and two-factor interaction plots are presented. ${ }^{15}$ The significance of each of the resulting terms was tested using a T-test with 0.050 as significance level. The null hypothesis for this test is that the effect of a specific term is zero. When the P-value for a specific term is smaller than 0.050 , we can reject the null hypothesis, concluding that the specific term is significant. 


\section{RESULTS AND DISCUSSION}

Figure 4 represents typical stress - strain curves obtained for samples produced with setting 8 and 16. There is a clear difference in adhesion strength for samples produced with the different settings. Also, the repeatability within the same setting can be observed.

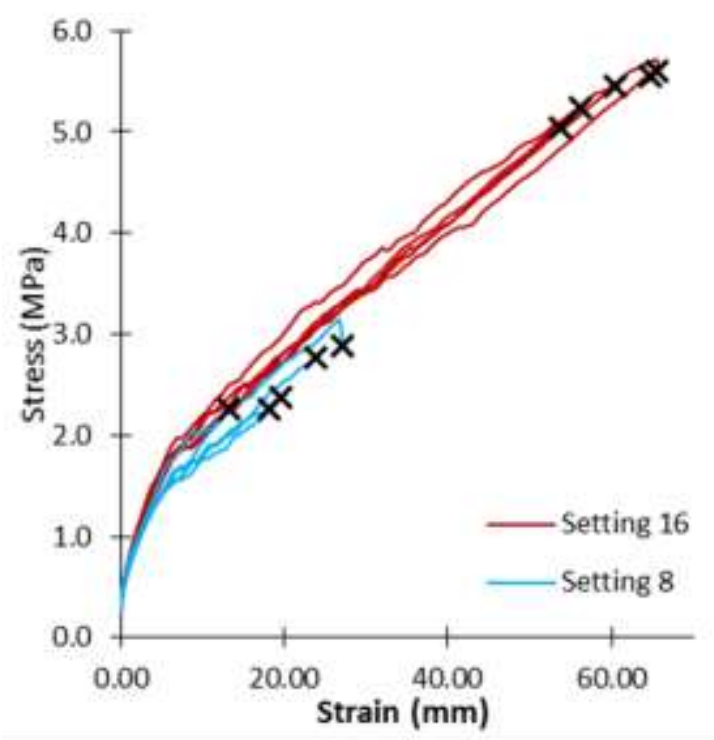

FIGURE 4 Example of typical tensile tests for setting 8 and 16.

Similar results were found for the other settings. The output from the design of experiment, as obtained with Minitab 17, is shown in Figure 5. It was verified that the observations are normally and independently distributed with the same variance in each factor level. This was done by examining the residuals. ${ }^{14}$

The main effect plot, presented in Figure 5a, indicates that the interface mould temperature has a large positive effect on the adhesion strength, ranging from 2.5 MPa to 5.3 MPa for respectively $129^{\circ} \mathrm{C}$ and $132{ }^{\circ} \mathrm{C}$. This effect is significant since the calculated P-value for this effect is 0.000 which is lower than 0.050 . Raising the injection temperature from $70^{\circ} \mathrm{C}$ to $80^{\circ} \mathrm{C}$, decreases adhesion strength from 4.0 MPa to 3.9 MPa. The P-value for this effect is 0.083 which is larger than 0.050 , making this effect non-significant. The positive effect of the injection speed is small, $3.9 \mathrm{MPa}$ and 4.0 for $59 \mathrm{~cm}^{3} / \mathrm{s}$ and $77 \mathrm{~cm}^{3} / \mathrm{s}$ respectively leading to a P-value of 0.358 which is not significant. An increased holding pressure enhances the adhesion strength, ranging from 3.8 MPa for 149 bar to $4.0 \mathrm{MPa}$ for 198 bar. With a P-value of 0.002 , this effect is significant. With a P-value of 0.515 , changing the roughness of the interface does not significantly affect the adhesion strength.

Two-factor interaction plots can be found in Figure 5b. Each column represents a different parameter for which every row shows the interaction plot with another parameter as indicated. None of the interaction terms are significant since the P-value for these terms ranges from 0.119 to 0.994 . When 
setting up an injection moulding process it is often required to adapt parameters in function of other parameters. For example, increasing the injection temperature requires lowering the holding pressure and injection speed to avoid flash. Lowering the mould temperature requires increasing the holding pressure, injection speed or injection temperature in order to avoid filling problems. The fact that in this study no two-factor interactions were found concerning the adhesion strength, facilitates the set-up of the process.

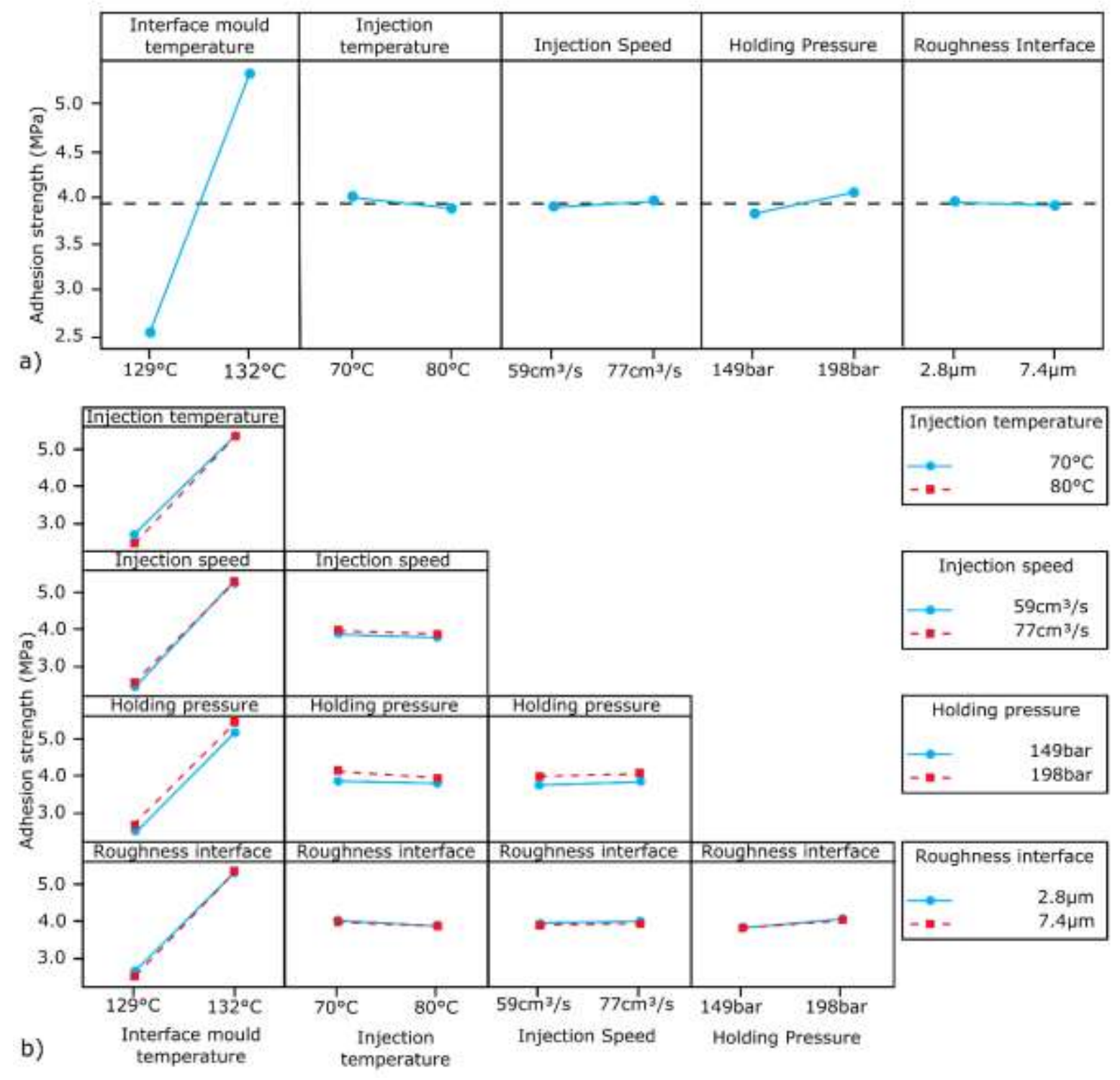

FIGURE 5 Main effects for the investigated process parameters are presented in a). In b) the twofactor interactions between the different process parameters can be found.

\section{Interface mould temperature}

As stated in literature, for two-component injection moulding of thermoplastics, the mould temperature will affect the temperature at the interface between the materials and therefore the

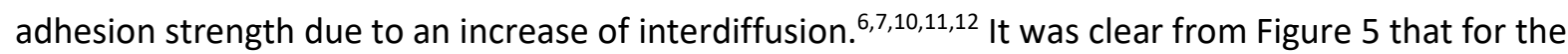


studied process and materials, the influence of the mould temperature is extremely high. For this specific process, mould temperatures are high compared to conventional injection moulding of thermoplastics. Therefore, the interface temperature of the materials is predominantly influenced by the mould temperature.

It is technically impossible to measure the interface temperature of the materials within the product. Simulations, using Autodesk Moldflow Insight 2018, were used to determine the resulting interface temperatures for the different settings. ${ }^{16}$ The executed simulations were verified by comparing the temperatures measured with the mould temperature sensors with the simulated values. Both measured and simulated values can be found in Table 3. Since these values are corresponding, it is expected that the simulated interface temperatures of the materials are correct. For mould temperatures at the interface of $129^{\circ} \mathrm{C}$ and $132{ }^{\circ} \mathrm{C}$, the resulting simulated interface temperatures of the materials in the middle of the part are respectively $123^{\circ} \mathrm{C}$ and $127^{\circ} \mathrm{C}$. This difference in temperature is responsible for the observed increase in adhesion strength.

TABLE 3 Measured and simulated temperatures for sensor T1 and T2 for both interface mould temperatures and resulting interface temperatures of the materials

\begin{tabular}{lcc}
\hline $\begin{array}{l}\text { Interface mould } \\
\text { temperature: }\end{array}$ & $129^{\circ} \mathrm{C}$ & $132{ }^{\circ} \mathrm{C}$ \\
\hline Sensor T1 simulated & $173^{\circ} \mathrm{C}$ & $174{ }^{\circ} \mathrm{C}$ \\
Sensor T1 measured & $172{ }^{\circ} \mathrm{C}$ & $173^{\circ} \mathrm{C}$ \\
Sensor T2 simulated & $55^{\circ} \mathrm{C}$ & $65{ }^{\circ} \mathrm{C}$ \\
Sensor T2 measured & $56{ }^{\circ} \mathrm{C}$ & $65^{\circ} \mathrm{C}$ \\
Interface temperatures & $123^{\circ} \mathrm{C}$ & $127^{\circ} \mathrm{C}$ \\
\hline
\end{tabular}

To study the effect of the mould temperature more extensively, samples were produced using five different mould temperatures at the interface. Each setting was repeated five times. Figure 6a shows the results for HDPE in combination with EPDM rubber. There is an almost linear effect of mould temperature on adhesion strength. When the temperature is too high, there is a decrease in adhesion strength. This decrease can be explained by small cavities at the interface which lower the contact surface between the two materials. The formation of similar small cavities is already described by Carella et al. ${ }^{11}$ for PP in combination with TPE. By analogy, small cavities are formed when the hot rubber is in contact with the solid thermoplastic material causing a higher temperature for the thermoplastic part at the interface in comparison with the bulk. The thermoplastic material close to the interface will expand more compared to the bulk due to the higher temperature. When the temperature is close to melting point, this difference in expansion will cause the formation of small cavities at the interface. With a sufficiently high holding pressure it could be possible to supress 
the formation of these cavities. However, for this specific product, the maximum useable holding pressure to produce samples without flash, was not high enough to completely remove the cavities.

To validate this dominant effect of the mould temperature, this experiment was repeated for NBR in combination with ABS which is, in contrast to HDPE, an amorphous polymer. Results are shown in Figure $6 \mathrm{~b}$. Also for this combination, the same effect of the mould temperature can be observed. For this material combination, the upper mould temperature was limited by deformation of the thermoplastic part in bulk when reaching bulk temperatures higher than the glass transition temperature $\left(100^{\circ} \mathrm{C}\right)$.
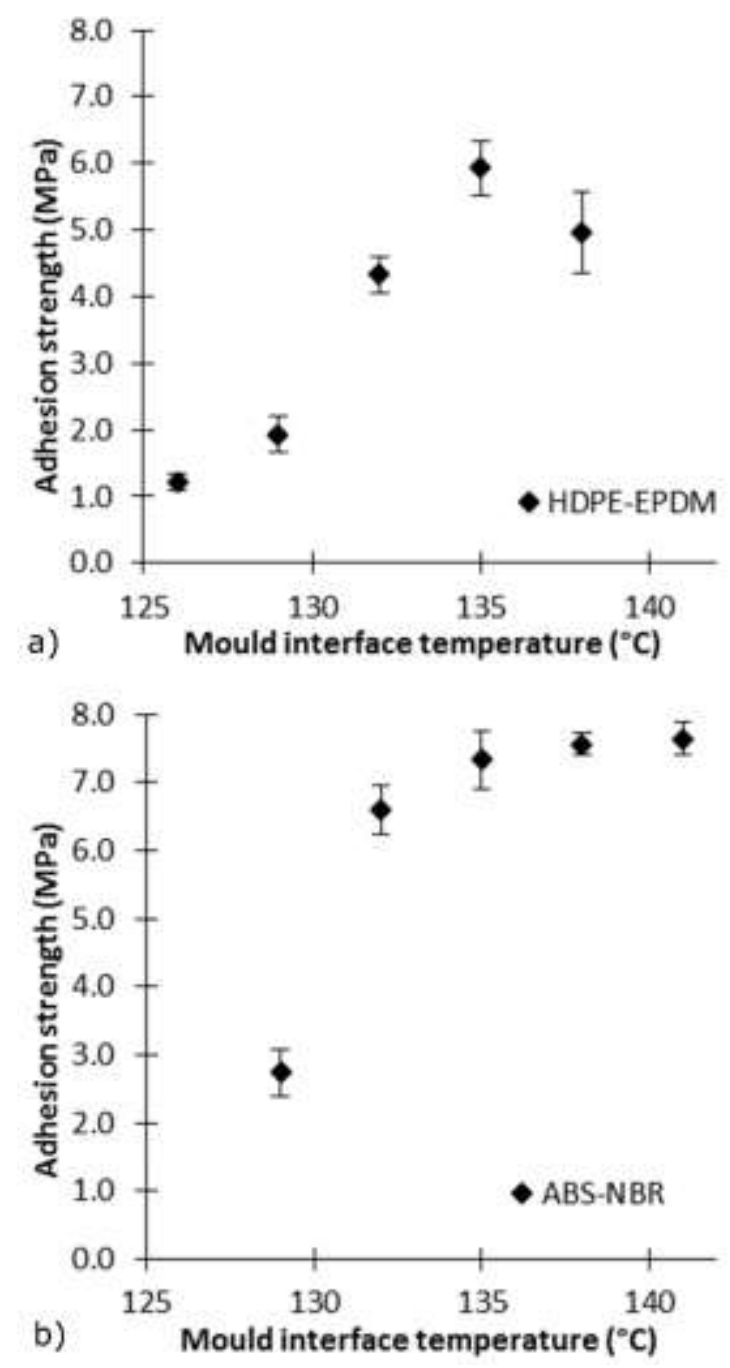

FIGURE 6 Representation of the adhesion strength in function of the mould interface temperature. In a) for HDPE with EPDM, in b) for ABS with NBR. The error bars represent the $95 \%$ confidence interval.

\section{Injection temperature}

For two-component injection moulding of thermoplastics, the injection temperature is the main parameter which influences the adhesion strength positively because it increases the interface 
temperature of the materials, melting them together. ${ }^{6,7,10,11}$ It was clear from Figure 5 that for the studied process, the injection temperature has a non-significant, negative effect on the adhesion strength. The injection temperatures for rubbers are low $\left(70^{\circ} \mathrm{C}-80^{\circ} \mathrm{C}\right)$ compared to the melting point of thermoplastics, making it impossible to directly melt the thermoplastics at the interface. ${ }^{1,3}$ Figure 7a presents the temperature profile, registered by the temperature sensors, during the injection of the rubber. The difference in temperature drop, caused by the material flowing into the mould, between an injection temperature of $80^{\circ} \mathrm{C}$ and $70^{\circ} \mathrm{C}$ is less than $1{ }^{\circ} \mathrm{C}$ for the same injection speed, making it impossible to significantly influence the resulting temperature at the interface of the materials.

From the pressure profile during the injection of the rubber, as shown in Figure $7 \mathrm{~b}$, it can be seen that the peak in pressure is lower for $80^{\circ} \mathrm{C}$ compared to $70^{\circ} \mathrm{C}$, for the same injection speed. This is a result of the lower viscosity of the rubber at a higher temperature. The non-significant, negative effect, is possibly caused by the lower pressure during the injection of the rubber for $80^{\circ} \mathrm{C}$ compared to $70^{\circ} \mathrm{C}$, as a higher pressure increases mechanical locking. 

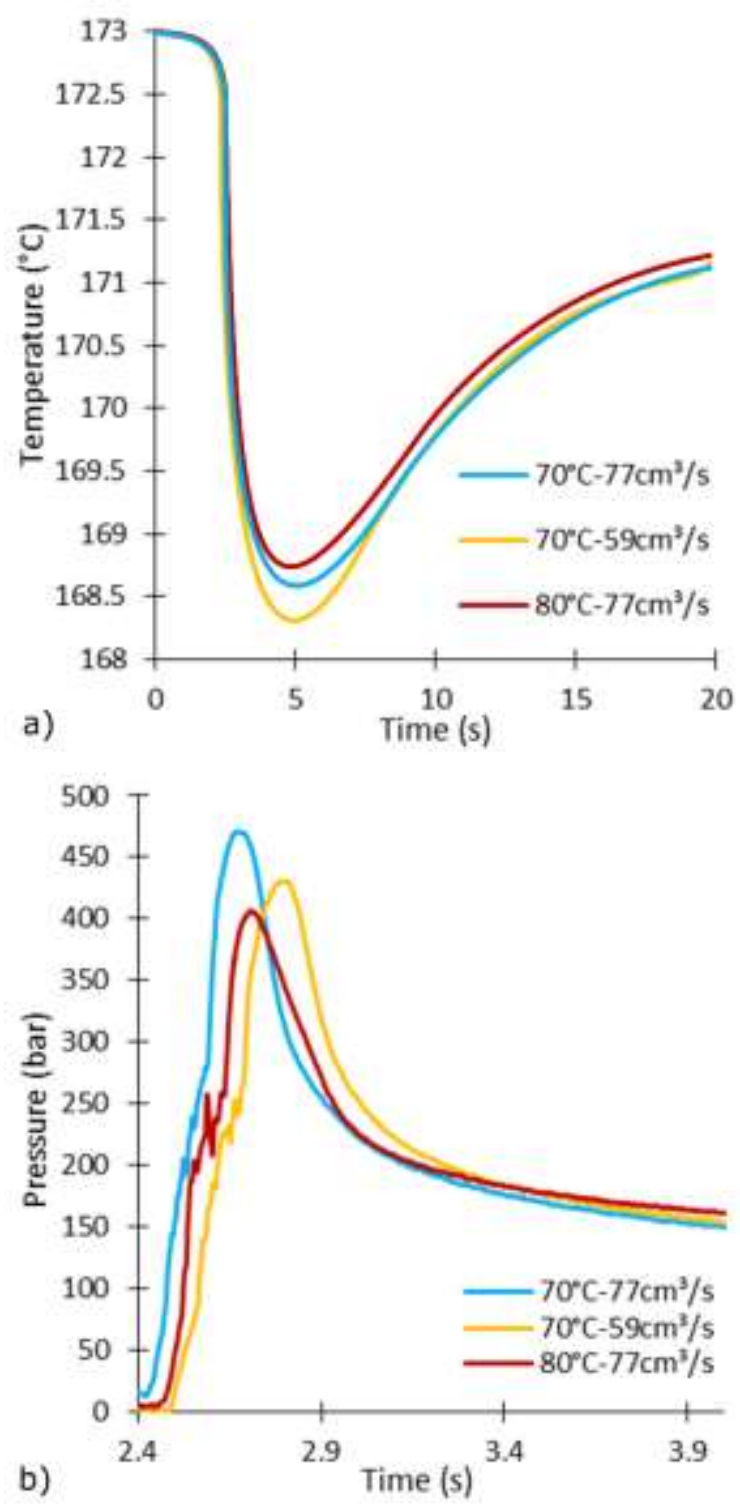

FIGURE 7 Temperature profiles measured with sensor T1 for different injection temperatures and speeds a). Pressure profile during injection for different injection temperatures and speeds measured with sensor P1 b).

\section{Injection speed}

According to Islam et al. ${ }^{6,7}$, higher injection speeds should increase the adhesion strength, for twocomponent injection moulding of thermoplastics, as a result of an increase in temperature due to shearing and due to a higher pressure resulting in more mechanical locking.

From Figure 7a, it can be seen that an increase in injection speed from $59 \mathrm{~cm}^{3} / \mathrm{s}$ to $77 \mathrm{~cm}^{3} / \mathrm{s}$ results in a small decrease in temperature drop, caused by the material flowing into the mould, of less than 1 ${ }^{\circ} \mathrm{C}$, which is too low to affect the adhesion strength significantly. The injection pressure for the different injection speeds is plotted in Figure $7 \mathrm{~b}$. The injection pressure increases with increasing 
injection speed. Therefore, the small positive difference in adhesion strength, due to the injection speed, is probably caused by a larger injection pressure which increases mechanical locking.

\section{Holding pressure}

A significant, but low, positive influence of the holding pressure was found in the present study. This effect is caused by an increase of mechanical locking by pressure. ${ }^{6,7}$ For thermoplastics, the holding pressure only affects the adhesion strength negatively when set too low or the holding pressure is not applied long enough. A further increment above the required values however, does not increase the adhesion strength.

During the actual design of experiment, only the amount of holding pressure was evaluated. To investigate the effect of holding phase more elaborate, samples were produced using the same holding pressure of 198 bar but different holding times for HDPE with EPDM. Each setting was repeated 5 times, resulting adhesion strengths are presented in Figure 8. From this figure it is clear that the adhesion strength is only affected when the holding time is zero, thus eliminating the holding phase. Even without holding pressure, the adhesion strength is relatively good, confirming the low influence of both amount of holding pressure and holding time.

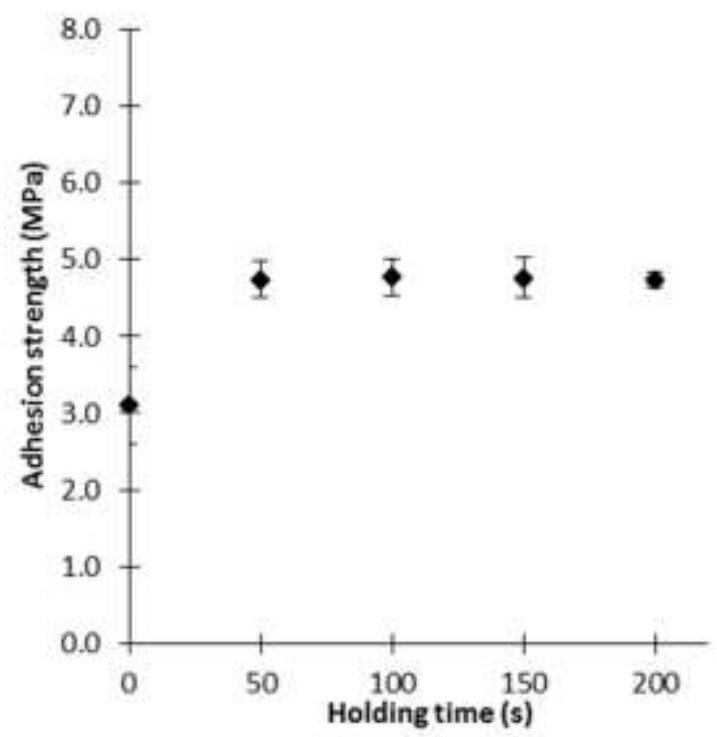

FIGURE 8 Adhesion strength in function of the holding time. The error bars represent the $95 \%$ confidence interval.

\section{Roughness interface}

Increasing the roughness of the interface increases the adhesion strength, when combining two thermoplastics, according to Islam et al. ${ }^{6,7}$ since a rougher surface increases both the mechanical locking as the total contact surface. It can be seen from Figure 5 that the adhesion strength is not affected by changing the roughness of the interface for this specific process. One possibility is that 
the roughness applied on the metal insert was not replicated by the thermoplastic part. To check this, the roughness of 20 thermoplastic parts produced with the different inserts were measured using a Diavite compact. The acquired roughnesses on both sets were $2.8 \pm 0.1$ and $7.4 \pm 0.2 \mathrm{Ra} \mu \mathrm{m}$. The generated roughness on the thermoplastic parts is thus significantly different. Possibly due to the high temperatures and long vulcanisations times, the interface melts and thereby eliminates the surface roughness. It is therefore impossible to create extra mechanical locking or increase of the contact surface by increasing the surface roughness.

\section{CONCLUSION}

In this study, the influence of the different process parameters on the adhesion strength between thermoplastics and thermoset rubber, was investigated for two-component injection moulding. The adhesion strength is mainly affected by the mould temperature at the interface. The mould temperature determines the interface temperature of the materials and it needs to be high enough to create sufficient bonding. However, the upper temperature of the mould is limited. For the material combination HDPE with EPDM, the upper temperature is limited by de formation of small cavities at the interface, caused by differential thermal contractions. For the combination of ABS with NBR, the upper temperature is limited by deformation of the thermoplastic part in bulk due to the high temperature. The effect of the holding pressure is only of importance when the value of the holding pressure or holding time is set too low. All other process parameters, injection temperature, injection speed and roughness of the interface, have no significant effect on the adhesion strength. Injection temperature and speed do not significantly increase the temperature of the rubber material and thus not increase the interface temperature. The roughness of the interface melts due to the high temperatures.

Because there is only one parameter with a large significant effect on the bond strength, namely the mould temperature at the interface, it is possible to use the other process parameters for the optimisation of the rubber part individually. In this way it is possible to produce parts with good dimensions and a good quality. Afterwards, the adhesion strength can be controlled using only the mould temperature at the interface.

\section{ACKNOWLEDGEMENTS}

G. Bex acknowledges Research Foundation - Flanders (FWO) and the Impulsfonds project financed by the KU Leuven, for funding his PhD grant Strategic Basic Research. The authors also acknowledge the company Hercorub NV for providing the uncured rubber material. 


\section{REFERENCES AND NOTES}

1. Ciesielski, A. An introduction to rubber technology, Rapra Technology Limited: Shawbury, 1999

2. Kamal, M.R., Isayev, A., \& Liu, S-J. Injection molding technology and fundamentals Hanser: Munich, 2009.

3. Lindsay, J.A. Practical guide to rubber injection moulding, Smithers Rapra: London, 2012.

4. Osswald, T.A., Turng, L.S., \& Gramann, P. Injection molding handbook, Hanser: Munich, 2008.

5. Bex, G., Desplentere, F., De Keyzer, J., \& Van Bael, A. International Journal of Advanced Manufacturing Technology. 2017, 92, 2599-2607.

6. Islam, A., Hansen, H. N., \& Bondo, M. International Journal of Advanced Manufacturing Technology. 2010, 50, 101-111.

7. Islam, A. Two component micro injection moulding formoulded interconnect devices, ph.D. thesis, Technical University of Denmark, February 2008.

8. Pompe, G., Brauer, M., Schweikle, D., Nagel, J., Hupfer, B., \& Lehmann, D. Journal of Applied Polymer Science. 2006, 100, 4297-4305.

9. Lindsay, J.A. Practical guide to rubber injection moulding, Smithers Rapra: London, 2012.

10. Huang, D. Y., \& Chen, R. S. Polymer Engineering and Science. 1999, 39, 2159-2171.

11. Carella, A. R., Alonso, C., Merino, J. C., \& Pastor, J. M. Polymer Engineering and Science. 2002, 42, 2172-2181.

12. Meister, S., \& Drummer, D. Microsystem Technologies-Micro-and Nanosystems-Information Storage and Processing Systems. 2017, 23, 1017-1025.

13. Bex, G., Seveno, D., De Keyzer, J., Desplentere, F. \& Van Bael, A. Journal of Applied Polymer Science. 2017, 135, 46046-46055.

14. Montgomery, D., Runger, G., \& Hubele, N. F. Engineering statistics, John Wiley \& Sons: Hoboken, 2012.

15. Minitab Inc. (2017). Minitab 17 (version 17.3.1) [Computer software], Pennsylvania: Minitab Inc. Available from http://www.minitab.com/en-us/

16. Autodesk Inc. (2017). Autodesk Moldflow Insight (version 2018) [Computer software], San Rafael: Autodesk Inc. Available from https://www.autodesk.com/products/moldflow 